\title{
Strategic Partnership of Independent States as a Game
}

\author{
Simona Hašková ${ }^{1, *}$ \\ ${ }^{1}$ The Institute of Technology and Business, School of Expertness and Valuation, Okržzní 517/10, \\ 37001 České Budějovice, Czech Republic
}

\begin{abstract}
The paper analyses the basic strategies of the international trade of two countries, analogous to the strategies of the market behaviour of two companies in the duopoly. The two-stage methodological approach was applied to analyse a problem. The first stage includes the formulation of an analytical tool in the form of an international trade model based on the model of comparative advantage whose outputs are transformed into the language of the game theory apparatus and presented by a payoff matrix. Based on the payoff matrix, the relevant analyses are then performed in the second stage. In analogy with market reality, two elementary game strategies were analysed - the strategy of cooperation and the myopic strategy. It has been shown that the cooperation based on the "cartel" model of two firms is to a certain extent an adequate description of the behaviour model of two co-trading countries provided that the input assumptions of game theory are not significantly violated. The article explains why the „foreign trade cartel“ is economically beneficial to all citizens of the trading countries unlike the cartel of companies operating within the same market, where the companies take key advantage from cooperation at the expense of consumer welfare.
\end{abstract}

Key words: international trade, cartel, strategic partnership, game theory

\section{Introduction}

Game theory, as a discipline of applied mathematics, analyses a wide range of conflicting (game) decision situations that can occur anywhere where conflicts of interest between stakeholders occur. The theoretical models analyse these conflicting situations, and based on the mathematical model of the conflict and with the help of calculations they try to find optimal strategies for the participants (players) of the strategic game. The basis of the analysis is to determine which strategy is the best answer to the strategy chosen by other players in terms of a particular criterion. If the criterion is the wealth maximization then the optimal response is a strategy that gives the player maximum benefit with regard to the chosen strategy of other player / players (e.g. [1] or [2]). The use of the conclusions of the game theory in practice is problematic, mainly because of the inconsistency between the model's initial assumptions (individualism, rationality and interdependence of participants in the conflict [3]), which co-determinate how things should evolve in contrast to

\footnotetext{
* Corresponding author: haskovas@post.cz
} 
phenomena occurring in society, which deny axioms of the game theory (bounded rationality [4], collectivism [5]).

If any normative theory in social sciences deviates from realistic assumptions, it necessarily converges to utopia [6]. Is this the case of game theory? The irrational behaviour of participants in decision-making situations in the theory of games has been studied by a number of authors. In Camerer, Ho and Chong [7] it was demonstrated on a choice of a number between 0 and 100 according to predefined rules (the player who determines the number closest to $2 / 3$ of the average of numbers chosen by all players wins the cash prize; in the case of more than one winner, the prize will be shared equally) that in the real world, a clear game theory strategy (on the basis of which all participants would choose the number 0 , and therefore the best strategy is to choose this number too) would not lead to the prize because the numerical average of the answers of the test groups ranged between 20 and 30. Other empirical research has shown that people are not economic maximizers but that they take into account the interests of others and are sensitive to standards of cooperation and justice; specifically, a robust test published in Jensen, Call and Tomasello [8] has shown that people will reject the proposed distribution of unexpected money gain at the expense of themselves if they consider it unfair (according to the theory of games, however the proposer will distribute the amount except the ratio $0: 100$ the optimal answer is to accept the offer, as ,something is always better than nothing“").

There are many other games, however, in which the players are very close to the state of equilibrium. One example is a stylized game of decision about entering a market in which $n$ players simultaneously decide whether to enter the market with a known market demand $d$ where $\mathrm{d}<\mathrm{n}$. Players prefer to enter the market if a total of $\mathrm{d}$ or fewer players enter the game; in the case $\mathrm{n}>\mathrm{d}$ they do not enter the market. The theory of market equilibrium states that the total number of players entering the market will be close to demand $d$, which corresponds to the real state of affairs in most markets (the equilibrium has also been achieved in one-off experiments, when for example, past experience that could lead to better results did not have the chance to be applied), see [9].

If theory delivers the optimal solution, why is its application in reality often unsuccessful? In Kahneman [10] a response was offered: by analysing two modes of thinking (logical and intuitive), a conclusion was come to that people are often unable to consider things in a deeper way and to think in a constructive and deductive way; they prefer rather to act intuitively and impulsively, which in the absence of experience in the given field can lead to irrational decisions. The solution that is offered is to lead individuals to consistency in thinking, not to rely by experience on unsubstantiated intuition and to learn from mistakes [11]. Another answer suggests that understanding the theory of games as a guide to the application of logical laws in an effort to maximize one's own benefits is incorrect and needs to be reassessed with respect to psychological realism [9], whose essence is that people behave psycho-logically rather than logically (this is based on peoples' wrong premise who assume that the others think similarly to themselves).

We have presented examples of individual decision-making in the field of game theory and the causes of the failure of its application, in which the style of thinking and the subjective aspects of individual psychology play a significant role. In the field of strategic decision-making of companies maximizing the profit, subjective aspects are eliminated in favour of maximizing the wealth of the firm owner, while the applied style of thinking is consistent with the desired goal and to a great extent corresponds to the principles of game theory [12].

Analogously with the strategic behaviour of companies, in the following it will be assessed whether game theory has its application in the strategic decision making of two countries as partners in foreign trade. For this purpose the impact of the cooperative and non-cooperative behaviour of partner countries on the development of the wealth of 
economies measured by the change in gross domestic product will be examined. The input macroeconomic model for the assessment of game strategies is the analysis of the comparative advantages resulting from the cooperation between two states. The purpose is to identify the prerequisites for functional cooperation of strategic partners in the spirit of game theory.

\section{Methodological approach to the analysis of the cooperative behaviour of two countries}

From the point of view of microeconomic theory, the cooperative duopoly is a market structure consisting of two producers who, on the basis of a collusive agreement on the quantity produced or price, divide the market. The fact that the duopoly agreement is unlawful and therefore legally unenforceable causes the duopolists to monitor their behaviour in order to detect a possible breach of the agreement and act accordingly [13]. This dependency property distinguishes duopoly (which is a special elemental form of a general oligopoly) from other market forms.

From a macroeconomic perspective, the duopoly market structure can be likened to an international cooperation agreement of two states, whose behaviour depends on compliance with conditions of the partnership, except that the partnership agreement between states is a legal treaty. In order to analyse the strategic behaviour of the two participants in international trade, it is necessary to adopt simplifying assumptions to construct a macroeconomic model of the consequences of the utilization of comparative advantages in the co-operation of states, whose conclusions will then be presented by a payoff matrix of the respective game:

- There are two countries involved in international trade. The engagement of other states will not be taken into account in the analysis;

- The states produce and trade two goods - food and textiles;

- The cost of acquirement of a standard unit of resources for producing these goods is the same in both countries;

- Production reaches the limit of their consumption possibilities (at the production possibility frontier curve (PPF)) in both countries and gross domestic product (GDP) is measured by the consumption method;

- In the different productions the same factor of production is equally productive in the given country;

- Two strategies at the level of international trade are taken into account - the strategy of cooperation (strict observance of the contractually agreed exchange ratio between the units of traded goods) and the myopic strategy (the attempt of the country to, at least in the short term, deflect the agreed exchange ratio to its advantage);

- The goal of states is to maximize the wealth measured by gross domestic product.

\section{Model of functioning of comparative advantage}

Let us consider two different sized and advanced closed economies, the economy of country A and the economy of country B, differing in the amount of standard resource units available (i.e. the combinations of land, labour and capital). Each of them produces two goods, food (F) and textiles (T), with the maximum number of units of these goods (UF and UT) that can be produced from one standard unit of resources as shown in Table 1 
Table 1. Output per unit of resources in countries $A$ and $B$ prior to the commencement of international trade

\begin{tabular}{|l|c|c|}
\hline Economy (country) & A & B \\
\hline Food (the number of UF) & 240 & 80 \\
\hline Textiles (the number of UT) & 60 & 40 \\
\hline
\end{tabular}

From Table 1 we see that the economy of country A is more efficient than the economy of country B in the production of both goods. It is 3 times more productive in food, but only 1.5 times in textiles. Therefore, it is comparatively better in food production. Similarly, although country B is worse in the production of both goods, it is less bad in textile production than in food; therefore it has a comparative advantage in textiles.

Let us define

- $\quad \mathrm{Cz} \ldots$ as a price of a standard resource unit in world currency (e.g. in \$);

- $\quad F_{A}, F_{B} \ldots$ as the number of UF produced from a standard resource unit in countries $\mathrm{A}, \mathrm{B}$;

- $\quad T_{A}, T_{B} \ldots$ as the number of UT produced from a standard resource unit in countries $\mathrm{A}, \mathrm{B}$;

- $\quad \mathrm{Cf}_{\mathrm{A}}=\mathrm{Cz} / 240, \mathrm{Cf}_{\mathrm{B}}=\mathrm{Cz} / 80, \mathrm{Ct}_{\mathrm{A}}=\mathrm{Cz} / 60, \mathrm{Ct}_{\mathrm{B}}=\mathrm{Cz} / 40 \ldots$ as prices of $\mathrm{UF}$ and $\mathrm{UT}$ in countries $\mathrm{A}, \mathrm{B}$.

Let us neglect the fact (in accordance with the fifth assumption in section 2) that in various productions the same production factors may be differently productive as a result of the economical transfer from one production to another, which shapes the production possibility frontier curve (PPF) as a concave curve. The production possibility frontier curves of countries $\mathrm{A}, \mathrm{B}$ at full employment of a standard unit of resources in the plane $(\mathrm{F}$, $\mathrm{T})$ can be thus graphically approximated by the line segments $\mathrm{Cz}=\mathrm{Cf}_{\mathrm{A}} \cdot \mathrm{F}_{\mathrm{A}}+\mathrm{Ct}_{\mathrm{A}} \cdot \mathrm{T}_{\mathrm{A}}, \mathrm{F}_{\mathrm{A}}$ $\geq 0, \mathrm{~T}_{\mathrm{A}} \geq 0$, or respectively $\mathrm{Cz}=\mathrm{Cf}_{\mathrm{B}} \cdot \mathrm{F}_{\mathrm{B}}+\mathrm{Ct}_{\mathrm{B}} \cdot \mathrm{T}_{\mathrm{B}}, \mathrm{F}_{\mathrm{B}} \geq 0, \mathrm{~T}_{\mathrm{B}} \geq 0$ with coordinates endpoints $(0,60),(240,0)$ and $(0,40)(80,0)-$ see Figure 1 . Each combination of quantities $\left(\mathrm{F}_{\mathrm{A}}, \mathrm{T}_{\mathrm{A}}\right)$, or respectively $\left(\mathrm{F}_{\mathrm{B}}, \mathrm{T}_{\mathrm{B}}\right)$ located on these line segments produces $\mathrm{GDP}=\mathrm{Cz}$, which means $100 \%$ of the possible output (e.g. if $\mathrm{F}_{\mathrm{B}}=20$, then $\mathrm{T}_{\mathrm{B}}=30$, hence $\mathrm{Cf}_{\mathrm{B}} 20+\mathrm{Ct}_{\mathrm{B}} \cdot 30=$ $\mathrm{Cz})$.

Let us assume that countries A and B will conclude a strategic partnership in which their economies will open to each other; each of them will devote to the production of the goods in which it gains a comparative advantage (i.e. country A will devote to food production, country B the textile production). These goods will be exchanged in a relaton 1 $\mathrm{UT}=3 \mathrm{UF}$. This international exchange relation is mutually beneficial as it ensures that what one wants to import the other wants to export:

the imported goods are cheaper than domestic (the food producer in country A pays for imported 1 UT only 3 UF, while 1 UT from domestic production costs 4 UF, since $\mathrm{Ct}_{\mathrm{A}}=4 \cdot \mathrm{Cf}_{\mathrm{A}}$; similarly, the textile producer in country $\mathrm{B}$ pays for imported 1 $\mathrm{UF}$ only UT / 3, whereas 1 UF produced domestically costs UT / 2 as $\mathrm{Cf}_{\mathrm{B}}=\mathrm{Ct}_{\mathrm{B}} /$ 2);

- the export yield is higher than from domestic sales (in country A the export revenue of $1 \mathrm{UF}$ equals $1 \mathrm{UF}=\mathrm{UT} / 3=\mathrm{Ct}_{\mathrm{A}} / 3=(\mathrm{Cz} / 60) / 3=\mathrm{Cz} / 180$, the yield of the sales of $1 \mathrm{UF}$ in the domestic market reaches $\mathrm{Cf}_{\mathrm{A}}=\mathrm{Cz} / 240$, in country $\mathrm{B}$ the export yield of $1 \mathrm{UT}$ equals $1 \mathrm{UT}=3 \cdot \mathrm{UF}=3 \cdot \mathrm{Cf}_{\mathrm{B}}=3 \cdot \mathrm{Cz} / 80=\mathrm{Cz} / 26.6$, whereas the yield on the sale of $1 \mathrm{UT}$ domestically is $\mathrm{Ct}_{\mathrm{B}}=\mathrm{Cz} / 40$ );

- Each country spends less resources on a given volume of imported goods than if it would be produced domestically (on imports of 1 UT country A spends $1 / 80$ of a standard resource unit, since $1 \mathrm{UT}=3 \cdot \mathrm{UF}=3 \cdot \mathrm{Cf}_{\mathrm{A}}=3 \cdot \mathrm{Cz} / 240=\mathrm{Cz} / 80$, whereas domestic production of 1 UT requires 1 / 60 of a standard resource unit, 
since $\mathrm{Ct}_{\mathrm{A}}=\mathrm{Cz} / 60$; country $\mathrm{B}$ spends on imports of $1 \mathrm{UF} 1 / 120$ of the standard resource unit, as $1 \mathrm{UF}=\mathrm{UT} / 3=\mathrm{Ct}_{\mathrm{B}} / 3=(\mathrm{Cz} / 40) / 3=\mathrm{Cz} / 120$, whereas home production of $1 \mathrm{UF}$ requires $1 / 80$ of the standard resource unit that has to be spent, since $\mathrm{Cf}_{\mathrm{B}}=\mathrm{Cz} / 80$ ).

As a result of the opening of two economies to each other and the commencement of mutual trade, the above Table 1 changes as follows:

Table 2. Output per unit of resources in countries A and B after the initiation of international trade

\begin{tabular}{|l|c|c|}
\hline Economy (country) & A & B \\
\hline Food (the number of UF) & 240 & 120 \\
\hline Textiles (the number of UT) & 80 & 40 \\
\hline
\end{tabular}

The value of $F_{B}$ has increased from the original 80 UF to 120 UF by means of producing $\mathrm{T}_{\mathrm{B}}=40 \mathrm{UT}$ from a standard resource unit in country $\mathrm{B}$, which were then exchanged in exchange ratio $1 \mathrm{UT}=3 \mathrm{UF}$ with country $A$ for $F_{B}=120 \mathrm{UF}$. Similarly, $\mathrm{T}_{\mathrm{A}}$ value has changed from the original 60 UT to $80 \mathrm{UT}$. From a standard resource unit it was first produced $\mathrm{F}_{\mathrm{A}}=240 \mathrm{UF}$ in country $\mathrm{A}$, which were then exchanged with country $\mathrm{B}$ for $\mathrm{T}_{\mathrm{A}}=\mathrm{F}_{\mathrm{A}} / 3=240 \mathrm{UF} / 3=80 \mathrm{UT}$.

The new frontier of production possibilities of the full standard resource unit employment thus became line segments in the plane $(\mathrm{F}, \mathrm{T})$ with the endpoints of the coordinates $(0,80),(240,0)$ and $(0,40),(120,0)$. Each combination of $\left(\mathrm{F}_{\mathrm{A}}, \mathrm{T}_{\mathrm{A}}\right)$ located at PPF of country A then produces GDP in the amount of the price 80 UT in country A, i.e. 80 $\mathrm{Ct}_{\mathrm{A}}=80 \mathrm{Cz} / 60=1.33 \mathrm{Cz}$. Compared with the closed economy, GDP in country A increased by one third. Analogically, any combination of the amount $\left(\mathrm{F}_{\mathrm{B}}, \mathrm{T}_{\mathrm{B}}\right)$ lying at PPF of country $\mathrm{B}$ produces GDP in the amount of the price $120 \mathrm{UF}$ in country $\mathrm{B}$, i.e. $120 \mathrm{Cf}_{\mathrm{B}}=$ $120 \mathrm{Cz} / 80=1.5 \mathrm{Cz}$. Compared with the closed economy, GDP has grown by half in country B (see the shift of the frontiers of production possibilities of country A and B in Fig. 1).

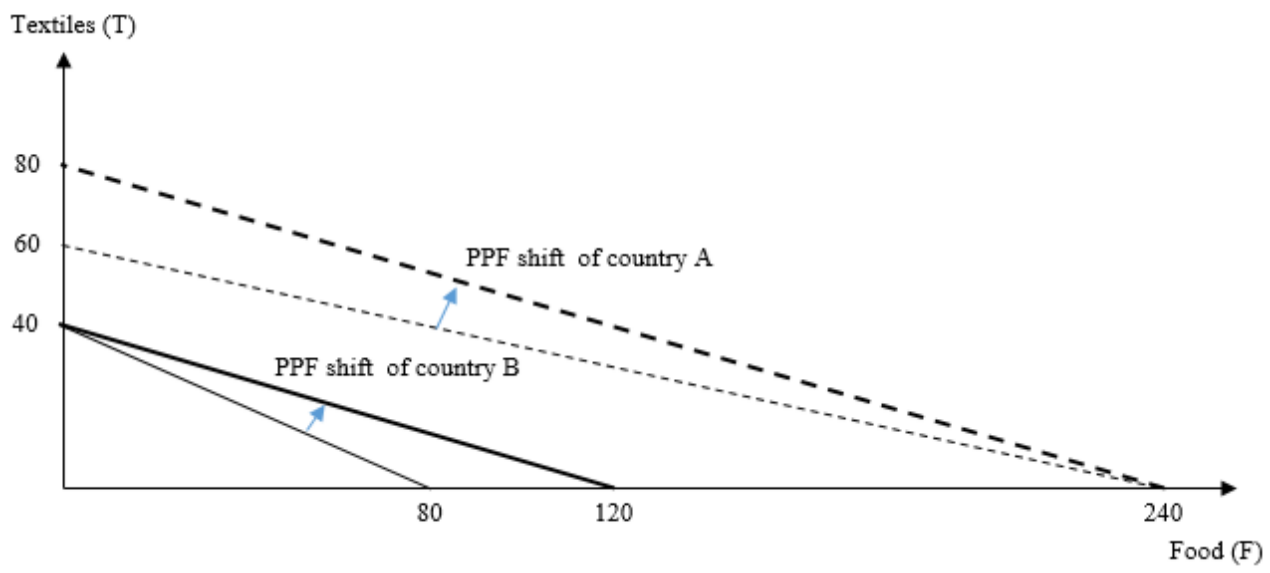

Fig. 1. The benefits of countries A and B from international trade illustrated as PPF shift

\section{Results: International trade as a game with a non-zero sum}


A game of non-zero sum is a game in which everyone can win if they cooperate. In the above-mentioned game of two players this was the case. Both countries agreed on an optimal exchange ratio lying in the middle between the opportunity costs of 1 UT (or 1 UF) in countries $\mathrm{A}$ and $\mathrm{B}$ from the perspective of the theory of comparative advantage. These are 4 UF in country A and 2 UF in country B (or respectively $1 / 4$ UT in country A and $1 / 2$ UT in country B). Therefore, the exchange ratio of $1 \mathrm{UT}=3 \mathrm{UF}$ has been chosen. From the viewpoint of the comparative advantage theory this is optimal as the less-developed economy $\mathrm{B}$ grows faster than the more developed economy $\mathrm{A}$, as a result of which the desired conversion occurs.

However, mutually beneficial is every exchange ratio UT: UF in the interval $(2,4)$. The closer to 2 , the relatively more advantageous (more profitable) the trade will be for country A than country $B$ and vice versa. In the case of the exchange ratio of $1 \mathrm{UT}=\sqrt{8} \mathrm{UF} \approx 2.83$ $\mathrm{UF}$ (this follows from the equality of ratios $40 \cdot \mathrm{x} \cdot \mathrm{Cz} / 80=240 / \mathrm{x} \cdot \mathrm{Cz} / 60$, where $\mathrm{x}$ signs for the exchange price) the original GDP grows by $41 \%$ in both economies after initiation of a trade. In the case of 1 UT $=2$ UF, the GDP of economy A doubles, while nothing changes in economy B compared to the state before opening to the trade. In the case of $1 \mathrm{UT}=4 \mathrm{UF}$, the GDP of economy B doubles, whereas nothing is changed in economy A. This leaves the space for competitive behaviour between countries to drag on the size of the exchange rate, whose possible (limit) results are recorded in the payoff matrix in Fig. 2.

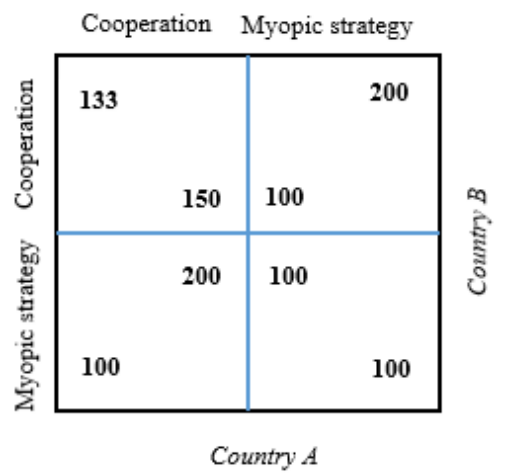

Fig. 2 Payoff matrix of benefits from foreign trade expressed in GDP growth (in \%) of countries $\mathrm{A}$ and $\mathrm{B}$

The payoff matrix exhibits this case: each of the countries can choose two strategies cooperation and limit myopic strategy. In the upper left quadrant both countries cooperate. We have focused on the clash of cooperation strategies of both countries so far, the consequence of which was a shift of PPF that increased the initial GDP from $100 \%$ of the potential of originally closed economies of both countries to a percentage GDP growth of open economies ( $133 \%$ in country A, $150 \%$ in country B) - see Fig. 1.

The essence of myopic (short-sighted) strategies lies in the fact that the country by deliberately generating trade deficits tries to deflect the exchange ratio to one's own benefit resulting in a drop of the GDP of the trade partner in behalf of own GDP growth. It can be assumed that the partner will not tolerate it and applies subsequently myopic conflicting strategy; in the case that the countries do not conclude a deal on any exchange rate once again, they end up in the bottom right-hand quadrant where the economies will close to each other in terms of the foreign trade - they will fall into trap of Nash equilibrium. 


\section{Discussion}

As the practice has shown, many companies with the intention to maximize their profits orient their strategies in order to gain market shares of their competitors. In Armstrong and Collopy [14] it was documented that such an effort may, however, damage the company's profitability. Their research has shown that out of twenty US companies the competitive firms have achieved lower returns on investment and the probability of their survival was lower than that of the companies that were not competitive. In the case of a limited number of ,players“ in the market who produce not substitutable or badly substitutable goods, a strategic market-sharing agreement, which is not legal in the economically developed countries, is the solution to prevent losses resulting from competitive market struggles (see [15], who analyses the post-cartel price during litigation). Detecting collusive agreements is difficult because collusive arrangements are usually hidden [16]. Unlike the collusive agreements of companies, whose strategies result in an increase in the socially undesirable deadweight loss, the collusive agreement of foreign trade partners is beneficial for the national economies in the long run.

This is illustrated by the above-described simple analysis of the payoff matrix of the contribution of two countries from foreign trade, where the GDP growth (\%) of country A is recorded in the marginal parts of the payoff matrix, the GDP growth (\%) of country B at the inner angles of the matrix (see Fig. 2). In the case of the cooperating countries in foreign trade, the GDP grew by $33 \%$, or respectively $50 \%$ (see the left upper quadrant) compared to the state before opening of economies to each other. The myopic competitive strategy (right upper and left bottom quadrant) brings a temporary advantage of GDP growth by $100 \%$ to country A, or respectively to country $\mathrm{B}$. The temporality of the advantage can be inferred from the fact that the legally enforceable contracts are a part of strategic partnership in foreign trade practice that severely disadvantage or penalize noncooperating behaviour - in our case the myopic behaviour. Penalty sanctions can ultimately lead the affected country to the withdrawal from the treaty, by means of which the economies find themselves in a pre-existing state before entering into trade cooperation see the bottom quadrant on the right the results of which correspond to the undesired Nash equilibrium. To prevent the trap of Nash equilibrium means to observe the terms of contractual cooperation and not to behave myopically.

\section{Conclusive summary}

The paper analysed two basic strategies in foreign trade - cooperation and myopic strategy in analogy with the strategic behaviour of companies in duopoly. In the first phase of the analysis a model of comparative advantages of two countries was constructed based on an agreement on mutual exchange of two goods (food and textiles) at a mutually advantageous exchange rate. The outputs of this model were transformed into a game theory apparatus the payoff matrix; the benefit of the mutual opening of economies was quantified by the percentage increase in GDP. The matrix showed the optimal strategic choice of the two countries - the orientation towards cooperation, which in the long run provides the countries with the desired benefits from international trade.

A unilateral violation of the cooperation by the application of a myopic strategy would very likely lead the ,affected“ country to the application of contractual sanctions contained in a binding trade agreement, which, unlike cartel cooperation of firms, is a legal document. In the extreme case, a breach of contract may lead to an end of cooperation resulting in a drop of GDP to the original level of closed economies - the trap of Nash equilibrium. In order to avoid the trap means to consistently follow the partners' agreement. Unlike cartel cooperation of firms, from which companies benefit at the expense of consumers and 
whose existence is associated with a socially undesirable occurrence of deadweight loss, two countries' tight cooperation enables, under certain circumstances shown in the paper, to increase the wealth of nations as a whole.

\section{References}

1. R. A. McCain, Game Theory, Edward Elgar Publishing, Drexel University, Philadephia, (2010)

2. D. M. Frankel, S. Morris, A. Pauzner, Equilibrium selection in global games with strategic complementarities. Journal of Economic Theory, 108(1), 1-44 (2003)

3. H. Singh, Introduction to game theory and its application in electric power markets, IEEE Computer Applications in Power, 12(4), 18-20 (1999)

4. D. Kahneman, A perspective on judgment and choice: Mapping bounded rationality. American psychologist, 58(9), 697-720 (2003)

5. M. B. Brewer, Y. R. Chen, Are Collectives in Collectivism? Toward Conceptual Clarification of Individualism and Collectivism. Psychological review, 114(1), 133151 (2007)

6. W. J. Samuels, J. E. Biddle, J. B. Davis (eds), A companion to the history of economic thought, Blackwell Publishing Ltd, John Wiley \& Sons (2008)

7. C. Camerer, T., J. Ho, J. Chong, A Cognitive Hierarchy Model of Games. Quarterly Journal of Economics, 119(3), 861-898 (2004)

8. K. Jensen, J. Call, M. Tomasello, Chimpanzees are rational maximizers in an ultimatum game. Science, 318, 107-109 (2007)

9. C. F. Camerer, Behavioral Game Theory: Experiments in Strategic Interaction, Princeton, NJ: Princeton University Press (2011)

10. D. Kahneman, Maps of Bounded Rationality: Psychology for Behavioral Economics. The American economic review, 93(5), 1449-1475 (2003)

11. S. Hašková, E. Babulak, M. Vochozka, Intellectual Capital Optimisation in Microeconomic Sphere. Proceedings of the 8th European Conference on Intellectual Capital: ECIC2016, p. 112-118 (2016)

12. M. J. Mazzeo. Product choice and oligopoly market structure. RAND Journal of Economics, 33(2), 221-242 (2002)

13. P. Billand, C. Bravard, S. Chakrabarti, S. Sarangi, A note on networks of collaboration in multi-market oligopolies. The Annals of Regional Science, 53(2), 325-335 (2014)

14. J. S. Armstrong, F. Collopy, Competitor Orientation: Effects of Objectives and Information on Managerial Decisions and Profitability, Journal of marketing research, 33(2), 188-199 (1996)

15. J. E. Harrington, Post-cartel pricing during litigation. The Journal of Industrial Economics, 52(4), 517-533 (2004)

16. R. H. Porter, Detecting Collusion. Review of Industrial Organization, 26(2), 147-167 (2005) 